Document downloaded from:

http://hdl.handle.net/10251/51793

This paper must be cited as:

Jordá Vilaplana, A.; Fombuena Borrás, V.; García García, D.; Samper Madrigal, MD.; Sánchez Nacher, L. (2014). Surface modification of polylactic acid (PLA) by air atmospheric plasma treatment. European Polymer Journal. (58):23-33. doi:10.1016/j.eurpolymj.2014.06.002.

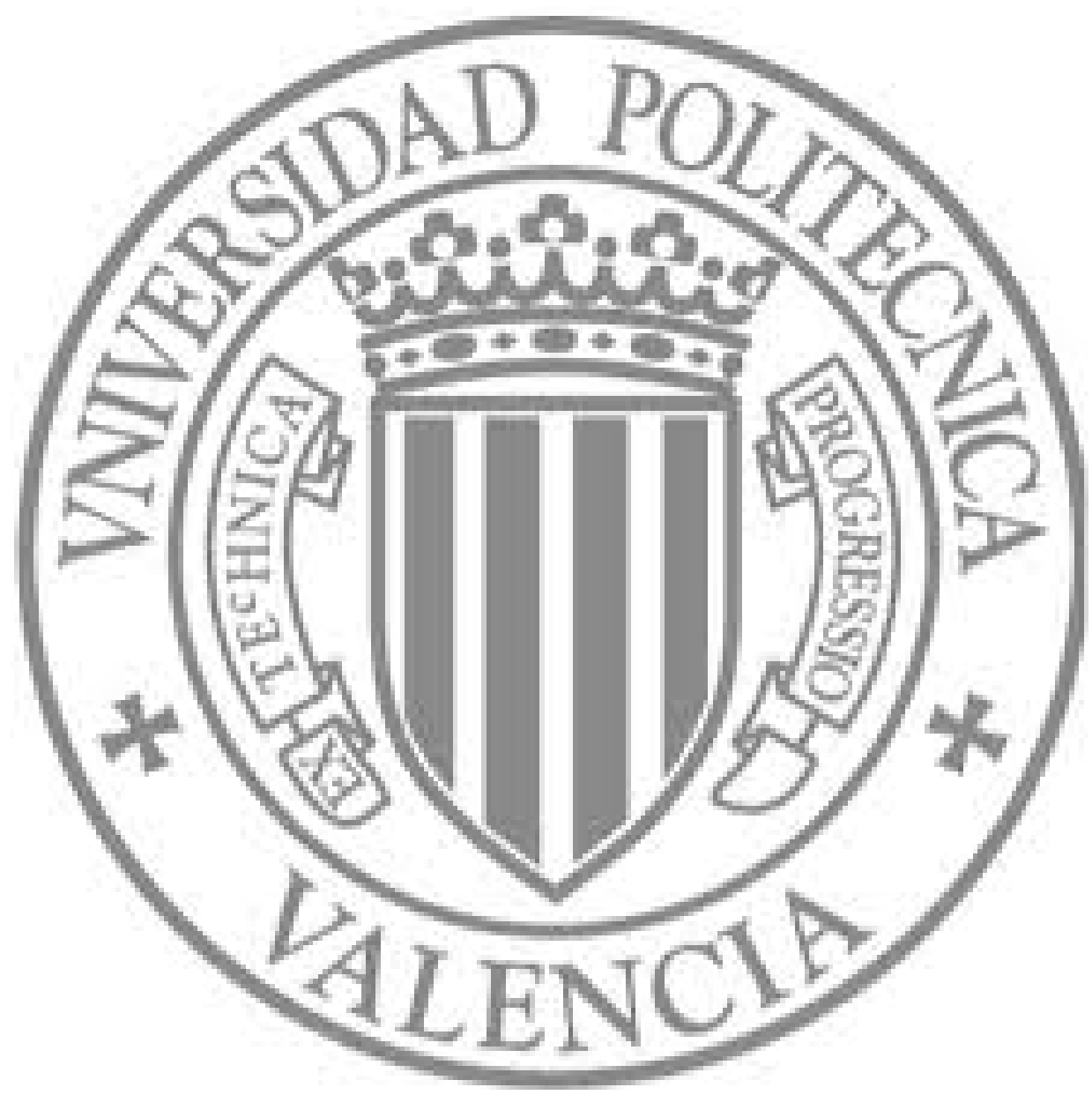

The final publication is available at

http://dx.doi.org/10.1016/j.eurpolymj.2014.06.002

Copyright Elsevier 


\title{
“Surface modification of polylactic acid (PLA) by air atmospheric plasma
}

\section{treatment”}

\author{
${ }^{a}$ Jordá-Vilaplana A, ${ }^{b}$ Fombuena $V,{ }^{b}$ García-García $D$, \\ ${ }^{b}$ Samper MD, ${ }^{b}$ Sánchez-Nácher L
}

\author{
åDepartamento de Ingeniería Gráfica (DIG) Teléfono:+34966528451 amjorvi@upv.es \\ Universitat Politècnica de València (UPV), 03801, Alcoy (Spain) \\ ${ }^{\mathrm{b}}$ Instituto de Tecnología de Materiales (ITM) \\ Universitat Politècnica de València (UPV), 03801, Alcoy (Spain)
}

\begin{abstract}
The main objective of this experimental study is the validation of the technique of atmospheric plasma with the aim of improving the surface energy of the polylactic acid (PLA) for further adhesion uses. The wettability of PLA has been improved with the application of an atmospheric plasma surface treatment. This method provides good adhesion properties with the optimizing the process parameters in terms of the nozzlesubstrate distance and sample advance rate. In order to achieve that goal, a new and environmentally friendly technology has been used which is based on the use of air atmospheric plasma. The effects of the surface treatment on this type of substrates have been analyzed. The macroscopic effects of the process parameters have been determined using contact angle measurements and subsequent surface free energy (SFE) calculation. In addition, the chemical changes at the topmost layers have been studied using X-ray photoelectron spectroscopy (XPS) and Fourier transformed infrared spectroscopy (FTIR). Surface topography changes due to the plasma-acting mechanisms
\end{abstract}


have been evaluated with scanning electron microscopy (SEM) and atomic force microscopy (AFM). The obtained results show a remarkable increase in surface free energy from $37.1 \mathrm{~mJ} \cdot \mathrm{m}^{-2}$ up to values of $60 \mathrm{~mJ} \cdot \mathrm{m}^{-2}$ thus indicating the effectiveness of the air plasma treatment. The main advantage of this technology is that the industrial process is continuous, it is easy to establish in current production systems and it does not generate wastes.

Keywords: atmospheric plasma; polylactic acid; wettability; surface topography;

\section{1.-Introduction}

The first driving force in the development and investigation of new biodegradable or ecological materials are the current environmental policies and the consumers conscience about the use and consumption of low environmental impact materials. Packaging industry is one of the main fields of waste production. New consumer trends in our society generate a great amount of waste that must be appropriately managed in order to produce the least environmental impact. Plastics, obviously, constitute an important part of this kind of wastes, and due to its petrochemical nature it is difficult and expensive to recycle, mainly because the problem of previous separation.

For this reason, polymeric materials are occupying important research lines due to the interest of substituting petroleum-based polymers by polymers obtained from renewable resources. [1-5]

Polylactic acid (PLA) is a biodegradable, compostable and renewable polymer. It is the second bioplastic produced on a broad scale after starch.PLA is a polyester formed by $100 \%$ of renewable raw materials, which is produced from lactic acid obtained by anaerobic fermentation of substrates that have carbon, either pure (glucose, lactose, etc.) 
or impure (starch, molasses, etc.) with microorganisms, such as Lactobacillus, Pediococcus, Lactococcus and Streptococcus bacteria or some kind of fungi, such as Rhizopus Oryzae. PLA is a transparent and colorless thermoplastic and it is quite similar in some aspects to polystyrene. It can be processed using the same processes of commodity plastics, mainly in the form of film and fiber. PLA has some interesting properties such as softness, erosion or scratch resistance and it is also stable towards ultraviolet rays. [2, 6-10] PLA has found increasing number of applications in the packing-packaging industry. These applications require in most cases surface hydrophilicity, as for example for surface finish, printing or ink primer, adhesion, etc., according to the product design. Due to the intrinsically low wettability of most polymeric materials, it is limited the possibility of applications in interesting packages for the final consumer.

There are different kinds of treatments for surface modification either physical or chemical. Generally, chemical treatments generate wastes because they use chemical products that attack the polymeric surface; that waste could be potentially harmful to the environment. For this reason, treatments that do not produce waste are more interesting. In this area, treatments based on plasma technology are optimal, because apart from being environmentally friendly, they selectively modify the topmost layers, without changing the bulk material. In the last years, the use of atmospheric plasma is growing in a remarkable way. Atmospheric plasma is produced by an electric shock in a gas that generates a source of electrons and activated (high energy) species characterized by high reactivity. When the activated species reach the substrate surface, new functional groups can be formed by the breaking up of the molecular chain; substitution and/or recombination of atoms can also be produced, being this most significant mechanism responsible of surface activation. Another plasma acting mechanism is microetching or 
surface abrasion. Physically it produces a surface micro-abrasion that contributes to a cleaning effect. If the gas used is oxygen, it can produce low molecular weight oxidized moieties (LMWOM) in the topmost layers of the polymeric substrate that can be easily removed. [11] The main advantages of atmospheric plasma respect other techniques, such as vacuum plasma, are that it works at room temperature in a continuous process that allows the implementation of this technology at the industry. Atmospheric plasma is a versatile technology, with uniform and reproducible results and it does not damage the environment because it does not generate waste. [12-16]

In this paper, the effects of atmospheric plasma processing conditions, nozzlesubstrate distance and advance rate, on PLA surface are assessed by determining the solid surface free energy (SFE) through contact angle measurements. The plasma acting mechanisms are analyzed from a chemical and physical viewpoint. The FTIR-ATR analysis is used in order to study surface functionalization provided by the atmospheric plasma. It is completed with analysis of X-rays photoelectron spectroscopy (XPS) which allows determining the overall oxidation level achieved by the surface treatment. Moreover; the physical modification of the material surface is quantified using two techniques: scanning electron microscopy (SEM) and atomic force microscopy (AFM). [16-26]

\section{2.-Experimental}

\section{1.-Materials}

The material used in this study is acommercial grade of polylactic acid (PLA) PLA 6201D supplied in pellet form by Nature Works LLC (Nature Works LLC, Minnesota, USA). The physical properties of PLA used are: Crystalline Melt Temperature 160$170^{\circ} \mathrm{C}$, Glass Transition Temperature $55-60^{\circ} \mathrm{C}$, density $1.4 \mathrm{~g} \cdot \mathrm{cm}^{-3}$, and $\mathrm{Mn} 217.000 \mathrm{Da}$. 
This material was injection molded in rectangular sheet form sizing $160 \times 60 \times 2.2 \mathrm{~mm}^{3}$ in an industrial injection molding machine Mateu \& Sole mod.270/5 (Mateu \& Sole, Barcelona, Spain). Then, the PLA sheets were cut to $20 \times 60 \times 2.2 \mathrm{~mm}^{3}$ samples for surface treatment.

Four different liquids were used for contact angle measurements and subsequent surface energy calculations. The liquids are: stabilized diiodomethane $99 \%$ of purity and supplied by Acros Organics (Acros Organics, Geel, Belgium), double distilled water, formamide and glycerol 99\%, extra pure for analysis (reagent grade) ACS from Scharlau Chemie S.A. (Scharlab S.L. Barcelona, Spain). The liquids with their constant surface tension values and their polar and dispersive components are shown in Table 1.

\section{Table 1}

\section{2.-Atmospheric plasma treatment}

An atmospheric plasma equipment "Plasma JetRD1004" supplied by Plasmatreat (Plasmatreat GmbH-Iberica, Barcelona, Spain). This model has a plasma generator, which works at $50 / 60 \mathrm{~Hz}, 230 \mathrm{~V}$ and $16 \mathrm{~A}$, with a discharge frequency of $17 \mathrm{kHz}$ and a discharge voltage of $20 \mathrm{kV}$. Moreover, it has a high-voltage transformer and a pressure controller. A circular nozzle with a rotation speed of $1900 \mathrm{rpm}$ was used for surface modification.

For surface treatment, PLA sheets were placed on the sample carrier and then, particular process conditions were applied. Atmospheric plasma was applied at different nozzle-substrate distances between 10 and $20 \mathrm{~mm}$ and at different sample advance rates ranging from 100 and $1000 \mathrm{~mm} \cdot \mathrm{s}^{-1}$. 


\section{3.-Chemical characterization of the surface}

Chemical changes achieved after the atmospheric plasma treatment were evaluated with Fourier-transformed Infrared Spectroscopy with attenuated total reflectance (FTIRATR) in a Brukermod. Vector 22 (Bruker Española S.A., Madrid, Spain). 200 scans between 4000 and $500 \mathrm{~cm}^{-1}$ at a step of $2 \mathrm{~cm}^{-1}$ were collected and averaged.

In addition, X-ray photoelectron spectroscopy was used for quantitative analysis of surface chemical changes produced by the atmospheric plasma treatment. XPS spectra were collected in a VG-Microtech Multilab equipment (VG Microtech Ltd., Uckfield, $\mathrm{UK})$ with a pass energy of $50 \mathrm{eV}$ and a radiation of $\mathrm{MgK} \alpha(1253.6 \mathrm{eV})$ anodic with constant mode of energetic analysis and a pressure of $5 \cdot 10^{-10}$ mbar. The $C(1 \mathrm{~s})$ was set to $284.6 \mathrm{eV}$. Binding energies (with accuracy of $\pm 0.2 \mathrm{eV}$ ) were obtained with the Peakfit software provided with the spectrometer.

\section{4.-Physical characterization of the surface}

The surface topography of the PLA samples with and without atmospheric plasma treatment were analyzed using a scanning electron microscope (SEM) model PHENOM (FEI Company, Eindhoven, The Netherlands) working at an electron acceleration of $5 \mathrm{kV}$. Prior to sample observation a sputter coating with a gold/palladium alloy was done in a Sputter Coater EMITECH mod. SC7620 (Quorum Technologies Ltd., East Sussex, UK). The thickness deposited in sputtering process is very thin $(5-7 \mathrm{~nm})$ and does not affect the results of the SEM. [27]

The surface roughness of the PLA samples was measured with atomic force microscopy (AFM) in a multimode AFM equipment with a nanoscope III a ADCS controller (Veeco Metrology Group, Cambridge, United Kingdom) and a silicon cantilever (Nano World Pointprobe ${ }^{\circledR} \mathrm{NCH}$ ) with a constant force of $42 \mathrm{~N} \cdot \mathrm{m}^{-1}$ and a 
resonance frequency of $320 \mathrm{kHz}$. The root-mean-squared roughness $\left(\mathrm{R}_{\mathrm{rms}}\right)$ was determined from collected images $20 \times 20 \mu^{2}$ in size. Every Rrms value has been determinate as an average of samples in each treatment condition.

The weight of PLA has been determined measuring samples with analytical balance METTLER TOLEDO AG245 (Barcelona, Spain) before and after plasma treatment. Error values were obtained by performing an average of 5 measurements for each treatment condition.

\section{5.-Characterization of the surface wettability}

In order to measure the contact angle it was used the Easy drop Standard KRÜSS goniometer (KRÜSS, GmbH, Hamburg, Germany), model FM140 (110/220 V, $50 / 60 \mathrm{~Hz}$ ). This model has a precision of $\pm 0.1^{\circ}$ and a measurement range of angle between $1-180^{\circ}$. In order to determine the contact angle the Drop Shape Analysis SW21 (DSA1) software was used. At least 10 measurements were taken for each sample and average values were calculated with a standard deviation less than $4 \%$.

The surface free energy can be experimentally determined by using different test liquids for contact angle measurements and subsequent application of a mathematical model. In this study the Owens-Wendt method is used; this estimates the surface free energy of a solid by using a linear approximation of the general expression for the surface energy proposed by Fowkes; in addition, this method allows determining the polar $\left(\gamma_{s}^{p}\right)$ and dispersive $\left(\gamma_{s}{ }^{d}\right)$ contributions to total surface free energy $\left(\gamma_{s}\right)$ by this equation. $[12,21,28]$

$$
\gamma_{1} \cdot(1+\cos (\theta))=2\left(\gamma_{s}^{d} \cdot \gamma_{1}^{d}\right)^{1 / 2}+2\left(\gamma_{s}^{p} \cdot \gamma_{1}^{p}\right)^{1 / 2}
$$


In this equation $\theta$ is the contact angle, $\gamma_{1}$ the surface tension of the liquid and $\gamma_{\mathrm{s}}$ the surface tension of the solid or surface free energy. The terms with the superscripts "d", and "p»" are the dispersive and polar component of surface free energy.

\section{3.-Results and discussion}

\section{1.-Chemical modification of the substrate surface of polylactic acid (PLA)}

Fig. 1 shows the FTIR-ATR spectra of the PLA substrate before and after doing the atmospheric plasma treatment, in order to analyze the treatment effects in a comparative way.

\section{Figure 1}

In the figure were observed 4 representative peaks: at $1750 \mathrm{~cm}^{-1}$ corresponding to $\mathrm{C}=\mathrm{O}$, at $1188-1090 \mathrm{~cm}^{-1}$ corresponding to $\mathrm{C}-\mathrm{O}$, at $1452-1368 \mathrm{~cm}^{-1}$ corresponding to $\mathrm{C}-\mathrm{O}-\mathrm{H}$ and at $3000 \mathrm{~cm}^{-1}$ corresponding to $\mathrm{C}-\mathrm{H}$. It has not been observed big differences between the PLA spectrum without treatment and the treated one at a nozzle-substrate distance of $10 \mathrm{~mm}$ and an advance rate of $100 \mathrm{~mm} \cdot \mathrm{s}^{-1}$. An increase in the intensity of the peaks $\mathrm{C}-\mathrm{O}, \mathrm{COOH}, \mathrm{C}=\mathrm{O}$ occurs; that it means, an increase in the intensity of oxygen related species can be detected which is representative of surface oxidation due to plasma effects. FTIR-ATR gives qualitative evidence of surface oxidation due to plasma treatment.

Fig. 2 shows the low resolution XPS spectra of untreated PLA and PLA samples treated with atmospheric plasma at a nozzle-distance of $10 \mathrm{~mm}$ and different sample advance rates. The XPS spectrum for untreated PLA shows two main contributions corresponding to $\mathrm{C}(1 \mathrm{~s})$ at $285 \mathrm{eV}$ and $\mathrm{O}(1 \mathrm{~s})$ located at $533 \mathrm{eV}$ due to the chemical 
structure of PLA which is characterized by the presence of oxygen in the polymeric chain. [1, 29-32]

\section{Figure 2}

In the above figure it can be observed that for a nozzle-substrate distance of 10 $\mathrm{mm}$, comparing it with the untreated sample, it can be clearly seen an increase in the peak intensity corresponding to the $\mathrm{O}(1 \mathrm{~s})$ transition, with a binding energy of $533 \mathrm{eV}$ and a decrease in the peak $\mathrm{C}(1 \mathrm{~s})$ contribution at $285 \mathrm{eV}$. Moreover, it is observed the appearance of a small peak that corresponds to the contribution of nitrogen, $\mathrm{N}(1 \mathrm{~s})$, with a binding energy of $399 \mathrm{eV}$ that did not appear in the untreated sample. This phenomenon occurs due to the use of atmospheric plasma which generates greats amounts of highly unstable species derived from oxygen and nitrogen in the air; so that functionalization will be produced by the insertion of species in the air; mainly species rich in oxygen due to its high reactivity and in a lower extent, species with presence of nitrogen. [33] At higher sample advance rates, the $\mathrm{O}(1 \mathrm{~s})$ peak height decreases thus indicating lower functionalization. Table 2 shows the values of the atomic composition obtained by XPS analysis for different nozzle-substrate distances and several advance rates.

\section{Table 2}

Regarding the atomic percentage of carbon of the first sample, comparing it with the samples treated with plasma at a nozzle-substrate distance of $10 \mathrm{~mm}$, it is observed the decrease of the atomic percentage for all advance rates. This effect is due to the 
increase in other functionalities on the surface and to the loss of species of low molecular weight because of oxidation (LMWOM-low molecular weight oxidized moieties) due to the breakage of polymeric chains on the topmost layers of PLA because of the action of plasma.[13, 34, 35]

It is worth mentioning the important increase in the atomic percentage of oxygen, with maximum values that almost twice the initial value for the untreated material, changing from $19 \%$ (untreated sample) to nearly $33 \%$ (sample treated with an advance rate of $100 \mathrm{~mm} \cdot \mathrm{s}^{-1}$ and $10 \mathrm{~mm}$ of nozzle-substrate distance). With these conditions there is a high oxidation level on the PLA surface, which is reduced when the advance rate increases. Regarding the presence of nitrogen on the surface of the treated PLA, it is very little in all cases. It should be taking into consideration that these species are derived from the nitrogen present in the air of the atmospheric plasma system.

The oxidation level of the PLA surface, measured as the $\mathrm{O} / \mathrm{C}$ ratio is representative for the functionalization effects due to the atmospheric plasma treatment. The $\mathrm{O} / \mathrm{C}$ ratio for a sample treated at $10 \mathrm{~mm}$ nozzle-substrate distance achieves high values at low advance rates $\left(100 \mathrm{~mm} \cdot \mathrm{s}^{-1}\right)$ with a value of 0.49 , which is remarkable higher than the $\mathrm{O} / \mathrm{C}$ ratio for the untreated material close to 0.25 . As the advance rate increases, the $\mathrm{O} / \mathrm{C}$ ratio decreases up to values of 0.31 for an advance rate of 1000 $\mathrm{mm} \cdot \mathrm{s}^{-1}$. This is due to the fact that with low advance speeds, the treatment is more effective since lower rates leads to higher exposure times to atmospheric plasma. This tendency is similar for other nozzle-substrate distances: i.e. for a nozzle-substrate distance of $14 \mathrm{~mm}$ and advance rate of $100 \mathrm{~mm} \cdot \mathrm{s}^{-1}$ the $\mathrm{O} / \mathrm{C}$ value is 0.39 , and this value decreases as the advance rate increases. 
Fig. 3a shows the high resolution XPS spectrum for untreated PLA sample without treatment, with the deconvolution of the $\mathrm{C} 1 \mathrm{~s}$ peak into three main contributions. The first one around $284.6 \mathrm{eV}$ corresponds to $\mathrm{C}-\mathrm{C}$ and $\mathrm{C}-\mathrm{H}$. The second peak around $286 \mathrm{eV}$ matches to species formed by carbon atoms single-bonded to oxygen atoms (CO). Finally, a smaller third contribution appears at a binding energy of $288.5 \mathrm{eV}$, corresponding to species in which the carbon atom is double-bonded to oxygen atoms $(\mathrm{C}=\mathrm{O}, \mathrm{O}-\mathrm{C}=\mathrm{O}) .[15,34,36,37]$

\section{Figure 3}

Some differences can be found when it is compared the C (1s) peak of the untreated PLA surface with the plasma-treated PLA surface (nozzle-substrate distance= $10 \mathrm{~mm}$; advance rate $=100 \mathrm{~mm} \cdot \mathrm{s}^{-1}$ ) as observed in Fig. $3 \mathrm{~b}$. It shows the same three contributions located at the same binding energies of $284.6 \mathrm{eV}(\mathrm{C}-\mathrm{C}$ and $\mathrm{C}-\mathrm{H}), 286 \mathrm{eV}$ (C-O) and $288.5 \mathrm{eV}(\mathrm{C}=\mathrm{O}, \mathrm{O}-\mathrm{C}=\mathrm{O})$, but it shows a different peak with binding energies near $287 \mathrm{eV}$ that could correspond to functionalities of imine groups $(\mathrm{C}=\mathrm{N}) .[34,38]$

Regarding the insertion of oxygen-based species, the optimal values are obtained at a nozzle-substrate distance of $10 \mathrm{~mm}$. For this distance, the $\mathrm{O} / \mathrm{C}$ ratio is higher in all the treated samples compared to the untreated samples. As the advance rate and nozzlesubstrate distance increases less oxidation ratio is produced. The higher insertion of polar species are hydroxyl groups $(-\mathrm{OH})$, hyperoxide groups $(\mathrm{C}-\mathrm{O}-\mathrm{O}-\mathrm{H})$ and ether $(-\mathrm{C}-$ O-C). At a lesser extent it is possible to obtain more oxidized species such as carboxylic acids (-COOH) and esters (-COO-R). 


\subsection{Topography changes on PLA surface due to atmospheric plasma treatment}

The SEM image corresponding to the untreated PLA (Fig. 4a) is characterized by a homogeneous surface, soft and a uniform appearance. Any kind of surface roughness could not be seen. No any remarkable topography is observed or any discontinuity on the surface. It has been taken into consideration that this surface is obtained after an injection process in a mold with a mirror finishing quality, which provides it with the surface uniformity. Nevertheless, the image of the PLA surface treated at an advance rate of $100 \mathrm{~mm} \cdot \mathrm{s}^{-1}$ and a nozzle-substrate distance of $10 \mathrm{~mm}$ (Fig. 4b) shows a different surface topography, comparing it with the untreated one.

\section{Figure 4}

Small spots were observed where the substrate suffered material removal due to formation of low molecular moieties which can be removed during plasma treatment or after the plasma treatment and subsequent surface cleaning; thus some material removal happened and it produced some changes in roughness. For these particular treatment conditions, a quite homogeneous surface topography was observed, with some zones where there can be some material removal. In general, it shows a uniform appearance due to the low aggressiveness of the atmospheric plasma treatment. [18, 39, 40]

Fig. 5 shows a 3D plot representation of PLA surface $\left(20 \times 20 \mu \mathrm{m}^{2}\right)$ obtained by AFM for a constant nozzle-substrate distance of $10 \mathrm{~mm}$ and different advance rates in the $100-1000 \mathrm{~mm} \cdot \mathrm{s}^{-1}$ range. Changes in surface topography are clearly revealed by using this technique. The surface roughness $\left(\mathrm{R}_{\mathrm{rms}}\right)$ of the untreated PLA is close to $12.1 \mathrm{~nm}$ and the maximum roughness achieved was $195.4 \mathrm{~nm}$. 


\section{Figure 5}

It can be observed comparatively changes in the surface topography of the treated PLA with atmospheric plasma under different conditions. The samples treated at low advance rates have a more irregular topography. When higher advance rates are used, the microetching effect is lower, so that the surface abrasion is restricted as the global exposure time is lower.

The effects of the nozzle-substrate distance and the sample advance rate can be observed in Fig. 6. The use of low nozzle-substrate distance together with low advance rates leads to the highest values of roughness on the PLA surface. This is due to the fact that the overall exposure time to the plasma gas increases with these particular conditions. The highest roughness value $\left(\mathrm{R}_{\mathrm{rms}}\right)$ is obtained, as expected, for a nozzlesubstrate distance of $10 \mathrm{~mm}$ and an advance rate of $100 \mathrm{~mm} \cdot \mathrm{s}^{-1}$, with a value of $56.9 \mathrm{~nm}$ which is more than four times of the initial value for the untreated PLA surface (12.1 $\mathrm{nm})$. For this particular advance rate and higher nozzle-substrate distance the surface roughness is still higher than the untreated material with $R_{\text {rms }}$ values of about $34 \mathrm{~nm}$. A clear tendency is observed since as the advance rate increases, the $\mathrm{R}_{\mathrm{rms}}$ values decrease.

\section{Figure 6}

The action of atmospheric plasma produces changes in topography due to some material removal which induces an increase in surface roughness. The aggressiveness of the plasma-etching mechanism can be followed by the mass loss. In Table 3 we show the measures of weight loss for different conditions of plasma atmospheric treatment. 


\section{Table 3}

First, it is noteworthy that the highest percentage is obtained for the most aggressive conditions as described before (low nozzle-substrate distance and low advance rate) since these conditions allow a higher micro mass removal. As the exposure time (directly related to low advance rates) and the plasma influence area (directly related to nozzle-substrate distance) increases, much more breaks of polymeric chains, thus leading to formation of low molecular weight oxidized moieties that can be removed from the topmost layers. [37, 41-43]

\section{3.-Changes in surface wettability on PLA surface}

In order to assess the effects of the different conditions of the atmospheric plasma the evolution of the contact angles for different test liquids has been carried out in terms of the atmospheric plasma main parameters.[21, 44-46] The contact angles obtained for the untreated PLA using the four test liquids are $73.4^{\circ}, 52.2^{\circ}, 40.9^{\circ}$ and $76.7^{\circ}$ for water, formamide, diiodoemethane and glycerol respectively. It should be considered that a surface with a water-contact angle between 0 and $30^{\circ}$ can be considered as hydrophilic whilst, a hydrophobic surface is characterized by contact angles over $90^{\circ}$. Therefore, the PLA surface behavior is quite hydrophobic as the initial contact angle (water) for the untreated surface is close to $73^{\circ}$.

Data obtained are plotted in Fig. 7 which shows the evolution of the contact angle in terms of the advance rate for different nozzle-substrate distances using four different test liquids.

\section{Figure 7}


The same tendency is observed for the four test liquids used if atmospheric plasma treatment is applied with a constant nozzle-substrate distance. If the advance rate is increased it produces an increase in the contact angles values.

By using the Owens-Wend method, the solid surface free energy $\left(\gamma_{\mathrm{s}}\right)$ and the corresponding polar $\left(\gamma_{\mathrm{s}}^{\mathrm{p}}\right)$ and dispersive $\left(\gamma_{\mathrm{s}}{ }^{\mathrm{d}}\right)$ contributions have been calculated. The solid surface energy of untreated PLA surface is close to $37.1 \mathrm{~mJ} \cdot \mathrm{m}^{-2}$, which can be separated into its two main component; the polar component $\left(\gamma_{\mathrm{s}}^{\mathrm{p}}\right)$ with low value about $6.8 \mathrm{~mJ} \cdot \mathrm{m}^{-2}$ and the dispersive contribution $\left(\gamma_{\mathrm{s}}{ }^{\mathrm{d}}\right)$ with relatively high value of $30.3 \mathrm{~mJ} \cdot \mathrm{m}^{-}$ ${ }^{2}$. Regarding the influence of the advance rate an increasing tendency is observed on surface free energy values as the advance rate decreases as it is shown in Table 4.

\section{Table 4}

The polar contribution decreases gradually as the advance rate increases. The dispersive component of the surface energy depends also on the advance rate but in a less important way than the polar component. The analysis of the data let us observe how the surface energy shows a remarkable increase, from low values of $37.1 \mathrm{~mJ} \cdot \mathrm{m}^{-2}$ for the untreated PLA surface sample, up to values of $58.9 \mathrm{~mJ} \cdot \mathrm{m}^{-2}$ for a plasma-treated PLA sample with the most aggressive conditions (nozzle-substrate distance $=10 \mathrm{~mm}$; advance rate $=100 \mathrm{~mm} \cdot \mathrm{s}^{-1}$ ). This represents almost a $59 \%$ increase in surface free energy with regard to untreated material. The polar contribution plays a key role in this overall increase in surface free energy as it changes from $6.8 \mathrm{~mJ} \cdot \mathrm{m}^{-2}$ for the untreated PLA surface up to values of $32.8 \mathrm{~mJ} \cdot \mathrm{m}^{-2}$ with the most aggressive conditions (nozzlesubstrate distance $=10 \mathrm{~mm}$; advance rate $=100 \mathrm{~mm} \cdot \mathrm{s}^{-1}$ ). With these particular treatment conditions, the polar contribution increases almost fivefold with respect to the polar 
component in the untreated sample. For less aggressive conditions at a nozzle-substrate distance of $10 \mathrm{~mm}$ and advance rate of $1000 \mathrm{~mm} \cdot \mathrm{s}^{-1}$ the increase in the total energy is much lower, reaching values close to $41.5 \mathrm{~mJ} \cdot \mathrm{m}^{-2}$, that is to say an increase of $12 \%$. On the other hand, the contribution of the dispersive component remains almost unaltered with the advance rate. This fact shows that the polar component presents a higher influence on the total surface free energy. For higher nozzle-substrate distances (14 and $20 \mathrm{~mm}$ ), the tendency is the same as observed for a distance of $10 \mathrm{~mm}$, but the increases are lower.

Fig. 8 shows graphically the influence of the two main control parameters of the atmospheric plasma treatment on the surface energy. A chromatic range is observed, which represent total surface energy $\left(\gamma_{\mathrm{s}}\right)$ as the result of the addition of polar $\left(\gamma_{\mathrm{s}}^{\mathrm{p}}\right)$ and dispersive contributions $\left(\gamma_{\mathrm{s}}{ }^{\mathrm{d}}\right)$. The red area represents the zone with the best results obtained in this study: nozzle-substrate distance of $10 \mathrm{~mm}$ and low advance rates between 100 and $500 \mathrm{~mm} \cdot \mathrm{s}^{-1}$ with surface energy values higher than $50 \mathrm{~mJ} \cdot \mathrm{m}^{-2}$. Green area represents values between $45 \mathrm{~mJ} \cdot \mathrm{m}^{-2}$ and $50 \mathrm{~mJ} \cdot \mathrm{m}^{-2}$. This zone represents conditions of treatment with good but less intense results. In blue and violet color the values of surface energy are around $45 \mathrm{~mJ} \cdot \mathrm{m}^{-2}$ and $35 \mathrm{~mJ} \cdot \mathrm{m}^{-2}$. This zone corresponds to conditions of treatment less effective. This conditions are distance of $10 \mathrm{~mm}$ and higher advance rate $\left(900-1000 \mathrm{~mm} \cdot \mathrm{s}^{-1}\right)$, distance of $14 \mathrm{~mm}$ and advance rate of $500-1000$ $\mathrm{mm} \cdot \mathrm{s}^{-1}$, and distance of $20 \mathrm{~mm}$ and advance rate between $200-1000 \mathrm{~mm} \cdot \mathrm{s}^{-1}$. This fact means that the wetting properties decrease because the effect of the atmospheric plasma is not as effective for high nozzle-substrate distances.

\section{Figure 8}




\section{4.- Conclusions}

Regarding the study of the polylactic acid surface activity, the study using FTIR and XPS shows that there is an insertion of polar groups in the PLA surface. The greater insertion of polar species are oxygen-based species and to a lesser extent highly oxidized species such carboxylic acids and esters.

With regard to changes in surface topography, the atmospheric plasma treatment causes a light increase in the surface roughness. The study using AFM confirms that increase occurs in a nanometric scale, reaching surface roughness values $\left(\mathrm{R}_{\mathrm{rms}}\right)$ of about $56.8 \mathrm{~nm}$ which is remarkable higher the surface roughness of the untreated material with $\mathrm{R}_{\mathrm{rms}} 12.1 \mathrm{~nm}$. A small weight loss occurs as a consequence of the plasma-etching mechanism but as we are working with sheets, the overall weight loss is relatively low $(<0.05 \%)$.

As a general conclusion, it is important to remark that the atmospheric plasma treatment improves the wettability of the PLA substrates. It is noteworthy the wettability obtained for a nozzle-substrate distance of $10 \mathrm{~mm}$ and an advance rate of $100 \mathrm{~mm} \cdot \mathrm{s}^{-1}$. With these conditions, the surface energy of the plasma-treated PLA reaches values over $60 \mathrm{~mJ} \cdot \mathrm{m}^{-2}$, almost twice than the value for the untreated sample with a surface energy of $37.1 \mathrm{~mJ} \cdot \mathrm{m}^{-2}$. In addition, it is important to remark that the polar contribution plays a key role in surface wettability as it increases up to $32.8 \mathrm{~mJ} \cdot \mathrm{m}^{-2}$ which is higher than the polar contribution in the untreated PLA sample $\left(6.8 \mathrm{~mJ} \cdot \mathrm{m}^{-2}\right)$. The dispersive component remains almost constant.

The results obtained in this study show that the best results achieved in the surface treatment with atmospheric plasma have been for conditions of low advance rate $\left[100-300 \mathrm{~mm} \cdot \mathrm{s}^{-1}\right]$ and low nozzle-substrate distances around $10 \mathrm{~mm}$. As it has been tested in the XPS results, the surface activation is the main mechanism in the PLA 
surface activation, due to the insertion of polar species (mainly oxygen-containing species). Finally, the results of this investigation show that atmospheric plasma is a suitable method to improve the hydrofilicity of PLA surface, as well as very interesting from an industrial point of view as it is a continuous process and does not generate wastes.

\section{Acknowledgment}

I wish to acknowledge the assistance in the completion of this article the Phd Rafael Antonio Balart Gimeno.

\section{Figure legends}

Figure 1.- FTIR-ATR spectra of the PLA substrate treated with atmospheric plasma with a nozzle-substrate distance of $10 \mathrm{~mm}$ and an advance rate of $100 \mathrm{~mm} \cdot \mathrm{s}^{-1}$ in comparison to untreated PLA sample.

Figure 2.-Low resolution XPS spectra of PLA sheets without treatment and treated with atmospheric plasma at a nozzle-substrate distance of $10 \mathrm{~mm}$ and $100 \mathrm{~mm} \cdot \mathrm{s}^{-1}$ advance rate.

Figure 3.- High resolution XPS spectra deconvolution of the C (1s) peak of: a) untreated PLA surface, and b)PLA surface treated with atmospheric plasma at a nozzlesubstrate distance of $10 \mathrm{~mm}$ and an advance rate of $100 \mathrm{~mm} \cdot \mathrm{s}^{-1}$.

Figure 4.- SEM images of the untreated PLA and treated PLA with distance nozzle/substrate of $10 \mathrm{~mm}$ and an advance rate of $100 \mathrm{~mm} \cdot \mathrm{s}^{-1} .(5000 \mathrm{x})$.

Figure 5.- AFM images (2D-left and 3D plots-right) of the untreated PLA surface and plasma-treated PLA surface at a constant nozzle-substrate distance of $10 \mathrm{~mm}$ and at different advance rates speeds (scale $20 \mu \mathrm{m}$ x $20 \mu \mathrm{m}$ ). 
Figure 6.-Comparative graph showing the evolution of the PLA surface roughness $\left(\mathrm{R}_{\mathrm{rms}}\right)$ obtained by AFM in terms of the advance rate for different nozzle-substrate distance.

Figure 7.-Variation of the contact angle on the PLA surface for different test liquids in terms of the advance rate for different nozzle-substrate distances: a) $10 \mathrm{~mm}$, b) $14 \mathrm{~mm}$ and c) $20 \mathrm{~mm}$.

Figure 8.-3D graphic representation of the surface energy $\left(\gamma_{S}\right)$ in terms of the control parameters of the atmospheric plasma treatment: nozzle-substrate distance and advance rate.

\section{Table legends}

Table 1.- Surface energy and its polar and dispersive components of different liquids for contact angle measurements.

Table 2.- Variation of the PLA surface composition treated in terms of the nozzlesubstrate distance and advance rate. (Data obtained from XPS analysis).

Table 3.- Average of the loss mass in $\%$ of the PLA samples treated with atmospheric plasma at different distances nozzle/substrate and variable advance rate.

Table 4.- Average of the loss mass in $\%$ of the PLA samples treated with atmospheric plasma at different distances nozzle/substrate and variable advance rate.

\section{References}

[1] Averous L. Biodegradable multiphase systems based on plasticized starch: A review. Journal of Macromolecular Science-Polymer Reviews. 2004;C44:231-74.

[2] Madhavan Nampoothiri K, Nair NR, John RP. An overview of the recent developments in polylactide (PLA) research. Bioresource Technology. 2010;101:8493-501.

[3] Siracusa V, Rocculi P, Romani S, Dalla Rosa M. Biodegradable polymers for food packaging: a review. Trends in Food Science \& Technology. 2008;19:634-43.

[4] Belard L, Poncin-Epaillard F, Dole P, Averous L. Plasma-polymer coatings onto different biodegradable polyesters surfaces. European Polymer Journal. 2013;49:882-92. 
[5] Zanden C, Voinova M, Gold J, Moersdorf D, Bernhardt I, Liu J. Surface characterisation of oxygen plasma treated electrospun polyurethane fibres and their interaction with red blood cells. European Polymer Journal. 2012;48:472-82.

[6] Ou X, Cakmak M. Comparative study on development of structural hierarchy in constrained annealed simultaneous and sequential biaxially stretched polylactic acid films. Polymer. 2010;51:783-92.

[7] Ou X, Cakmak M. Influence of biaxial stretching mode on the crystalline texture in polylactic acid films. Polymer. 2008;49:5344-52.

[8] Sodergard A, Stolt M. Properties of lactic acid based polymers and their correlation with composition. Progress in Polymer Science. 2002;27:1123-63.

[9] Slepicka P, Michaljanicova I, Kasalkova NS, Kolska Z, Rimpelova S, Ruml T, et al. Poly-L-lactic acid modified by etching and grafting with gold nanoparticles. Journal of Materials Science. 2013;48:5871-9.

[10] Slepicka P, Kasalkova NS, Bacakova L, Kolska Z, Svorcik V. Enhancement of Polymer Cytocompatibility by Nanostructuring of Polymer Surface. Journal of Nanomaterials. 2012.

[11] Prat R, Koh YJ, Babukutty Y, Kogoma M, Okazaki S, Kodama M. Polymer deposition using atmospheric pressure plasma glow (APG) discharge. Polymer. 2000;41:7355-60.

[12] Martinez-Martinez M, Romero-Sanchez MD. Strategies to improve the adhesion of rubbers to adhesives by means of plasma surface modification. European Physical JournalApplied Physics. 2006;34:125-38.

[13] Lee KT, Goddard JM, Hotchkiss JH. Plasma Modification of Polyolefin Surfaces. Packaging Technology and Science. 2009;22:139-50.

[14] Romero-Sanchez MD, Martin-Martinez JM. UV-ozone surface treatment of SBS rubbers containing fillers: Influence of the filler nature on the extent of surface modification and adhesion. Journal of Adhesion Science and Technology. 2008;22:147-68.

[15] Teraoka F, Nakagawa M, Hara M. Surface modification of poly(L-lactide) by atmospheric pressure plasma treatment and cell response. Dental Materials Journal. 2006;25:560-5.

[16] Fombuena-Borras V, Boronat-Vitoria T, Fenollar-Gimeno O, Sanchez-Nacher L, GarciaSanoguera D. OPTIMIZATION OF ATMOSPHERIC PLASMA TREATMENT OF LDPE SHEETS. Dyna. 2012;87:549-57.

[17] Slepicka P, Jurik P, Kolska Z, Malinsky P, Mackova A, Michaljanicova I, et al. A novel method for biopolymer surface nanostructuring by platinum deposition and subsequent thermal annealing. Nanoscale Research Letters. 2012;7.

[18] Slepicka P, Kasalkova NS, Stranska E, Bacakova L, Svorcik V. Surface characterization of plasma treated polymers for applications as biocompatible carriers. Express Polymer Letters. 2013;7:535-45.

[19] Slepicka P, Trostova S, Kasalkova NS, Kolska Z, Sajdl P, Svorcik V. Surface Modification of Biopolymers by Argon Plasma and Thermal Treatment. Plasma Processes and Polymers. 2012;9:197-206.

[20] Espana JM, Garcia D, Sanchez L, Lopez J, Balart R. Modification of surface wettability of sodium ionomer sheets via atmospheric plasma treatment. Polymer Engineering and Science. 2012;52:2573-80.

[21] Pascual M, Sanchis R, Sanchez L, Garcia D, Balart R. Surface Modification of Low Density Polyethylene (LDPE) Film Using Corona Discharge Plasma for Technological Applications. Journal of Adhesion Science and Technology. 2008;22:1425-42.

[22] Sanchis MR, Blanes V, Blanes M, Garcia D, Balart R. Surface modification of low density polyethylene (LDPE) film by low pressure 0-2 plasma treatment. European Polymer Journal. 2006;42:1558-68.

[23] Sanchis MR, Calvo O, Fenollar O, Garcia D, Balart R. Surface modification of a polyurethane film by low pressure glow discharge oxygen plasma treatment. Journal of Applied Polymer Science. 2007;105:1077-85. 
[24] Sanchis RM, Calvo O, Sanchez L, Garcia D, Balart R. Enhancement of Wettability in low density polyethylene films using low pressure glow discharge N-2 plasma. Journal of Polymer Science Part B-Polymer Physics. 2007;45:2390-9.

[25] Chvatalova L, Cermak R, Mracek A, Grulich O, Vesel A, Ponizil P, et al. The effect of plasma treatment on structure and properties of poly(1-butene) surface. European Polymer Journal. 2012;48:866-74.

[26] Gupta B, Krishnanand K, Deopura BL. Oxygen plasma-induced graft polymerization of acrylic acid on polycaprolactone monofilament. European Polymer Journal. 2012;48:1940-8.

[27] Slepicka P, Fidler T, Vasina A, Svorcik V. Ripple-like structure on PLLA induced by gold deposition and thermal treatment. Materials Letters. 2012;79:4-6.

[28] Michalski MC, Hardy J, Saramago BJV. On the surface free energy of PVC/EVA polymer blends: Comparison of different calculation methods. Journal of Colloid and Interface Science. 1998;208:319-28.

[29] Harris AM, Lee EC. Improving mechanical performance of injection molded PLA by controlling crystallinity. Journal of Applied Polymer Science. 2008;107:2246-55.

[30] Harris AM, Lee EC. Heat and Humidity Performance of Injection Molded PLA for Durable Applications. Journal of Applied Polymer Science. 2010;115:1380-9.

[31] Inkinen S, Stolt M, Sodergard A. Stability studies on blends of a lactic acid-based hot melt adhesive and starch. Journal of Applied Polymer Science. 2008;110:2467-74.

[32] Lim LT, Auras R, Rubino M. Processing technologies for poly(lactic acid). Progress in Polymer Science. 2008;33:820-52.

[33] Borris J, Dohse A, Hinze A, Thomas M, Klages C-P, Moebius A, et al. Improvement of the Adhesion of a Galvanic Metallization of Polymers by Surface Functionalization Using Dielectric Barrier Discharges at Atmospheric Pressure. Plasma Processes and Polymers. 2009;6:S258-S63.

[34] De Geyter N, Morent R, Jacobs T, Axisa F, Gengembre L, Leys C, et al. Remote Atmospheric Pressure DC Glow Discharge Treatment for Adhesion Improvement of PDMS. Plasma Processes and Polymers. 2009;6:S406-S11.

[35] Wielen LCV, Elder T, Ragauskas AJ. Analysis of the topochemical effects of dielectricbarrier discharge on cellulosic fibers. Cellulose. 2005;12:185-96.

[36] Abenojar J, Torregrosa-Coque R, Martinez MA, Martin-Martinez JM. Surface modifications of polycarbonate $(\mathrm{PC})$ and acrylonitrile butadiene styrene (ABS) copolymer by treatment with atmospheric plasma. Surface \& Coatings Technology. 2009;203:2173-80.

[37] Wang CQ, He XN. Polypropylene surface modification model in atmospheric pressure dielectric barrier discharge. Surface \& Coatings Technology. 2006;201:3377-84.

[38] Wang K, Wang W, Yang D, Huo Y, Wang D. Surface modification of polypropylene nonwoven fabric using atmospheric nitrogen dielectric barrier discharge plasma. Applied Surface Science. 2010;256:6859-64.

[39] Hwang YJ, Matthews S, McCord M, Bourham M. Surface modification of organic polymer films treated in atmospheric plasmas. Journal of the Electrochemical Society. 2004;151:C495C501.

[40] Kim JK, Kim HS, Lee DG. Adhesion characteristics of carbon/epoxy composites treated with low- and atmospheric pressure plasmas. Journal of Adhesion Science and Technology. 2003;17:1751-71.

[41] Choi WY, Lee CM, Park HJ. Development of biodegradable hot-melt adhesive based on poly-epsilon-caprolactone and soy protein isolate for food packaging system. Lwt-Food Science and Technology. 2006;39:591-7.

[42] Cui N-Y, Upadhyay DJ, Anderson CA, Meenan BJ, Brown NMD. Surface oxidation of a Melinex 800 PET polymer material modified by an atmospheric dielectric barrier discharge studied using X-ray photoelectron spectroscopy and contact angle measurement. Applied Surface Science. 2007;253:3865-71. 
[43] Zhou Z, Liu X, Hu B, Wang J, Xin D, Wang Z, et al. Hydrophobic surface modification of ramie fibers with ethanol pretreatment and atmospheric pressure plasma treatment. Surface \& Coatings Technology. 2011;205:4205-10.

[44] Takemura Y, Yamaguchi N, Hara T. Study on surface modification of polymer films by using atmospheric plasma jet source. Japanese Journal of Applied Physics. 2008;47:5644-7.

[45] Thurston RM, Clay JD, Schulte MD. Effect of atmospheric plasma treatment on polymer surface energy and adhesion. Journal of Plastic Film \& Sheeting. 2007;23:63-78.

[46] Borcia G, Anderson CA, Brown NMD. The surface oxidation of selected polymers using an atmospheric pressure air dielectric barrier discharge. Part II. Applied Surface Science. 2004;225:186-97.

\section{Figure legends}

Figure 1.- FTIR-ATR spectra of the PLA substrate treated with atmospheric plasma with a nozzle-substrate distance of $10 \mathrm{~mm}$ and an advance rate of $100 \mathrm{~mm} \cdot \mathrm{s}^{-1}$ in comparison to untreated PLA sample.

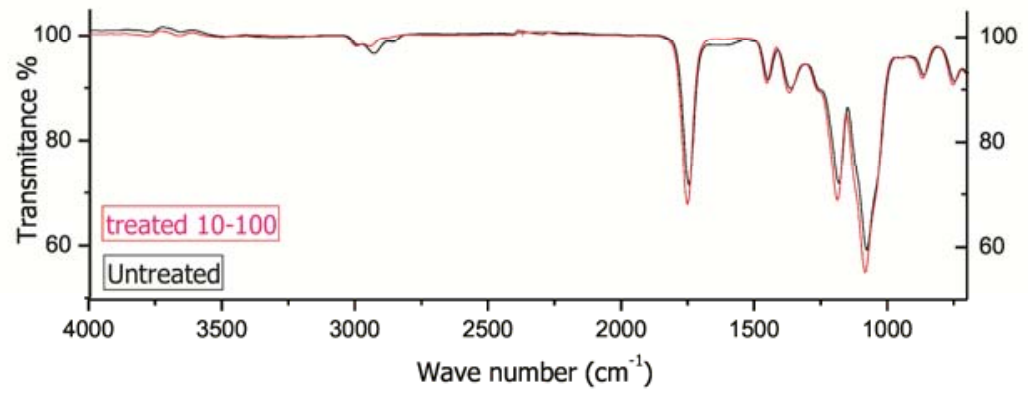

Figure 2.-Low resolution XPS spectra of PLA sheets without treatment and treated with atmospheric plasma at a nozzle-substrate distance of $10 \mathrm{~mm}$ and $100 \mathrm{~mm} \cdot \mathrm{s}^{-1}$ advance rate.

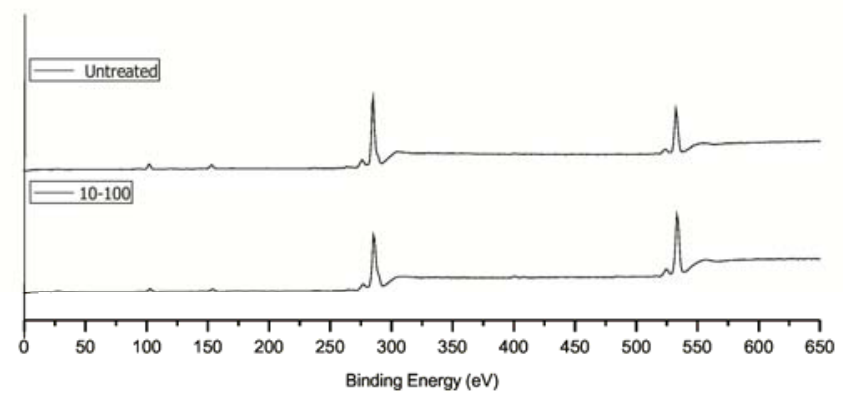


Figure 3.- High resolution XPS spectra deconvolution of the C (1s) peak of: a) untreated PLA surface, and b)PLA surface treated with atmospheric plasma at a nozzlesubstrate distance of $10 \mathrm{~mm}$ and an advance rate of $100 \mathrm{~mm} \cdot \mathrm{s}^{-1}$.
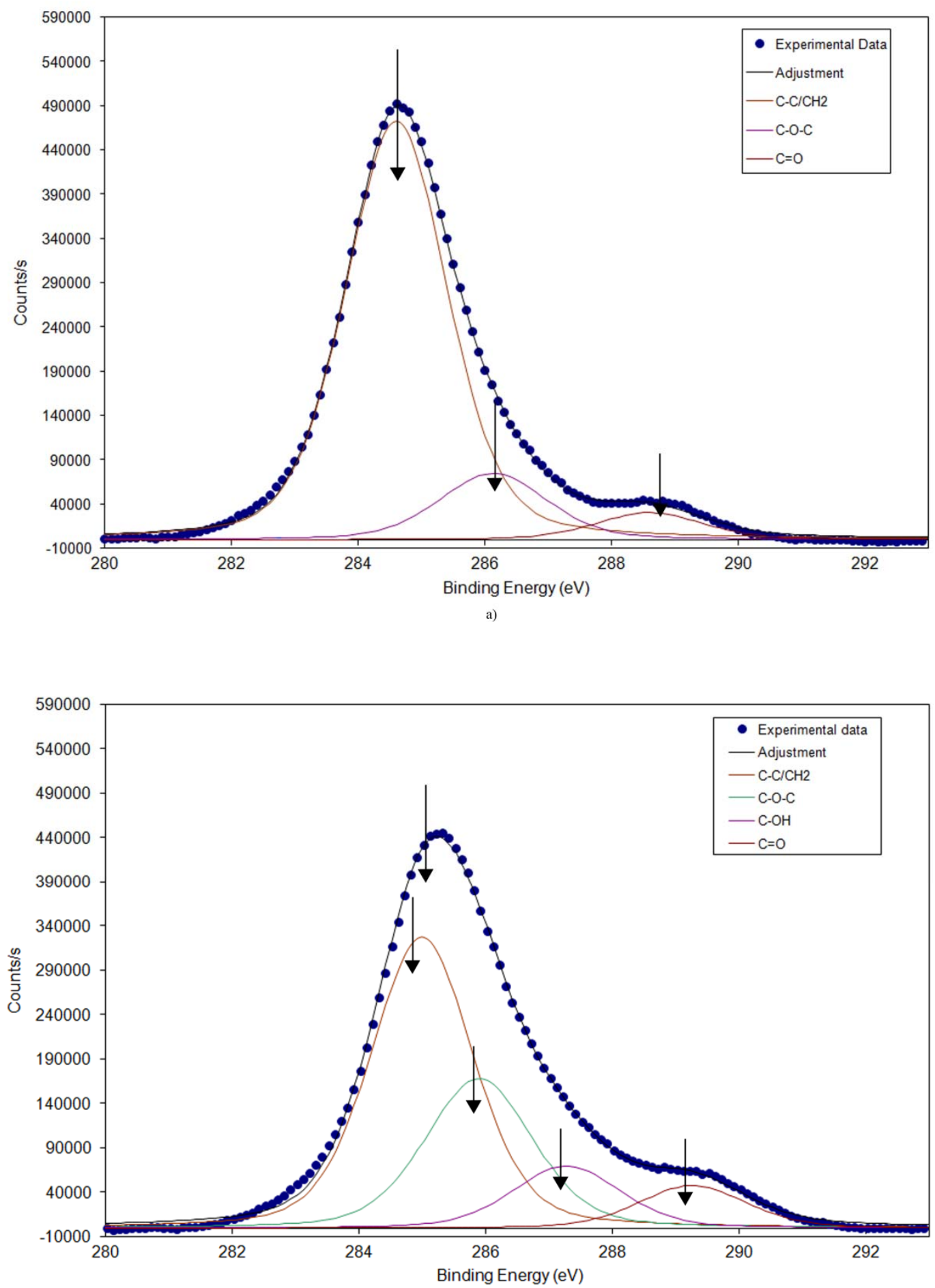

b) 
Figure 4.- SEM images of the untreated PLA and treated PLA with distance nozzle/substrate of $10 \mathrm{~mm}$ and an advance rate of $100 \mathrm{~mm} \cdot \mathrm{s}^{-1} .(5000 \mathrm{x})$.
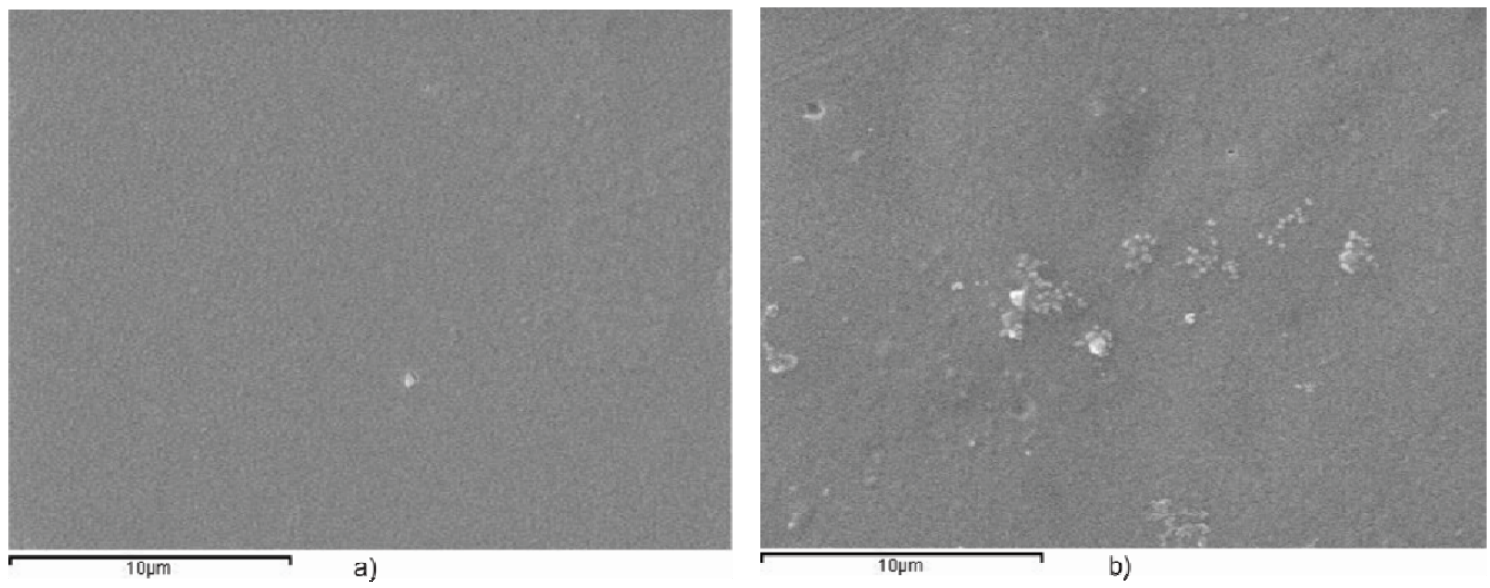
Figure 5.- AFM images (2D-left and 3D plots-right) of the untreated PLA surface and plasma-treated PLA surface at a constant nozzle-substrate distance of $10 \mathrm{~mm}$ and at different advance rates speeds (scale $20 \mu \mathrm{m}$ x $20 \mu \mathrm{m}$ ).
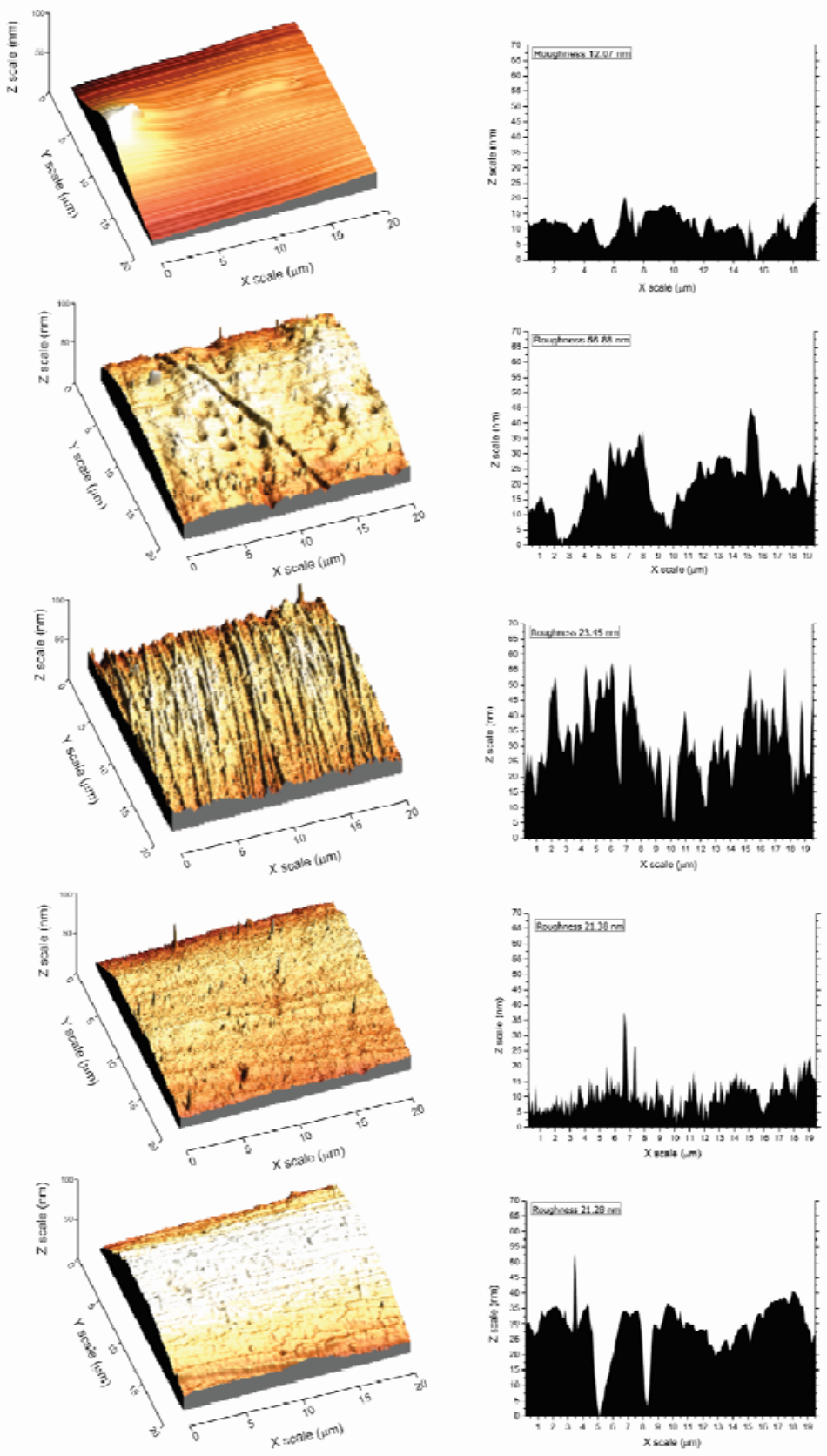
Figure 6.-Comparative graph showing the evolution of the PLA surface roughness $\left(\mathrm{R}_{\mathrm{rms}}\right)$ obtained by AFM in terms of the advance rate for different nozzle-substrate distance.

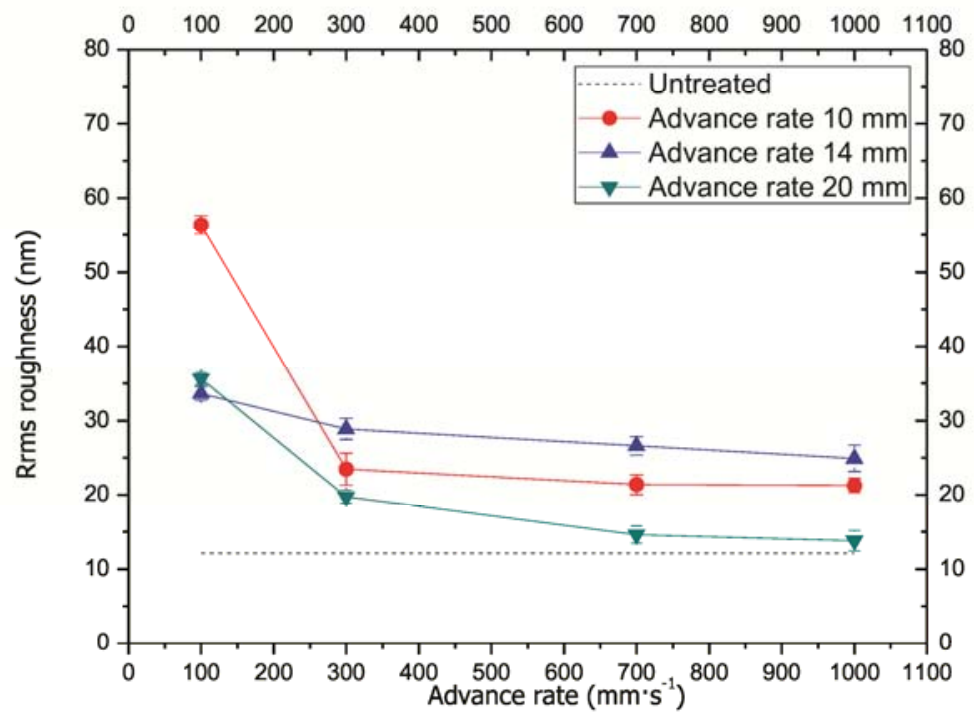


Figure 7.-Variation of the contact angle on the PLA surface for different test liquids in terms of the advance rate for different nozzle-substrate distances: a) $10 \mathrm{~mm}$, b) $14 \mathrm{~mm}$ and c) $20 \mathrm{~mm}$.
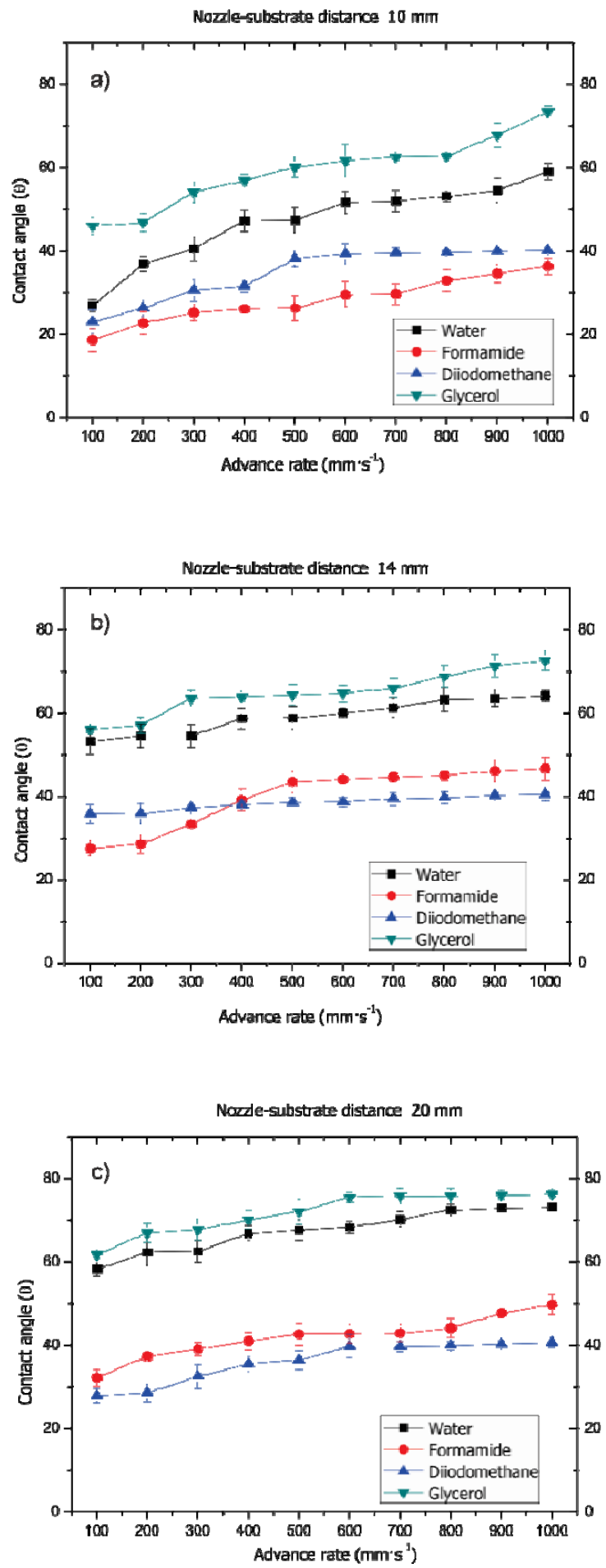
Figure 8.-3D graphic representation of the surface energy $\left(\gamma_{\mathrm{S}}\right)$ in terms of the control parameters of the atmospheric plasma treatment: nozzle-substrate distance and advance rate.

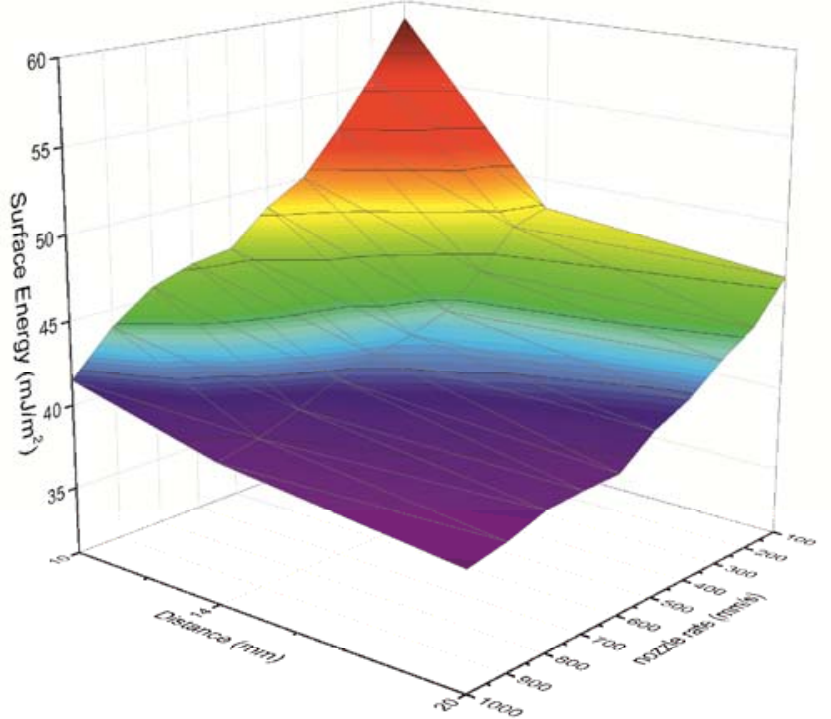

Table legends

Table 1.Tension energy and its polar and dispersive components of different liquids for contact angle measurements.

\begin{tabular}{|l|c|c|c|}
\hline Test liquid & $\gamma_{\mathrm{s}}^{\mathbf{d}}\left(\mathbf{m} \mathbf{J} \cdot \mathbf{m}^{-\mathbf{2}}\right)$ & $\gamma_{\mathrm{s}}^{\mathbf{p}}\left(\mathbf{m} \mathbf{J} \cdot \mathbf{m}^{-\mathbf{2}}\right)$ & $\gamma_{\mathbf{s}}\left(\mathbf{m} \mathbf{J} \cdot \mathbf{m}^{-2}\right)$ \\
\hline Water & 22.0 & 50.2 & 72.2 \\
\hline Glycerol & 34.0 & 30.0 & 64.0 \\
\hline Diiodomethane & 48.5 & 2.3 & 50.8 \\
\hline Formamide & 32.3 & 26.0 & 58.3 \\
\hline
\end{tabular}


Table 2.-Variation of the PLA surface composition treated in terms of the nozzlesubstrate distance and advance rate. (Data obtained from XPS analysis).

\begin{tabular}{|c|c|c|c|c|c|c|}
\hline $\begin{array}{l}\text { Nozzle-substrate } \\
\text { distance (mm) }\end{array}$ & $\begin{array}{l}\text { Advance } \\
\left(\mathrm{mm} \cdot \mathrm{s}^{-1}\right)\end{array}$ & $\begin{array}{c}\% \text { atomic } \\
\text { C }\end{array}$ & $\begin{array}{c}\text { \% atomic } \\
\text { O }\end{array}$ & $\begin{array}{c}\text { \% atomic } \\
\mathrm{N}\end{array}$ & Rate O/C & Rate N/C \\
\hline Untreated & & 76.1 & 18.9 & 0.4 & 0.25 & 0.005 \\
\hline \multirow{4}{*}{10} & 100 & 66.6 & 32.6 & 0.7 & 0.49 & 0.010 \\
\hline & 300 & 67.9 & 31.2 & 0.8 & 0.46 & 0.012 \\
\hline & 700 & 71.5 & 27.4 & 1.1 & 0.38 & 0.016 \\
\hline & 1000 & 75.6 & 23.6 & 0.8 & 0.31 & 0.010 \\
\hline \multirow{6}{*}{14} & 100 & 70.8 & 27.8 & 1.4 & 0.39 & 0.019 \\
\hline & 300 & 76.9 & 22.7 & 0.4 & 0.29 & 0.005 \\
\hline & 700 & 77.3 & 22.6 & 0.1 & 0.29 & 0.001 \\
\hline & 1000 & 81.6 & 17.9 & 0.4 & 0.22 & 0.005 \\
\hline & 100 & 69.3 & 30.3 & 0.4 & 0.44 & 0.005 \\
\hline & 300 & 69.1 & 30.5 & 0.4 & 0.44 & 0.005 \\
\hline \multirow[t]{2}{*}{20} & 700 & 79.6 & 20.1 & 0.3 & 0.25 & 0.004 \\
\hline & 1000 & 81.8 & 17.8 & 0.4 & 0.22 & 0.002 \\
\hline
\end{tabular}


Table 3.- Average of the loss mass in \% of the PLA samples treated with atmospheric plasma at different distances nozzle/substrate and variable traverse speeds.

\begin{tabular}{|c|c|c|}
\hline $\begin{array}{l}\text { Nozzle-substrate } \\
\text { distance (mm) }\end{array}$ & Advance rate $\left(\mathrm{mm} \cdot \mathrm{s}^{-1}\right)$ & $\%$ Mass loss \\
\hline \multirow{4}{*}{10} & 100 & 0.053 \\
\hline & 300 & 0.052 \\
\hline & 700 & 0.052 \\
\hline & 1000 & 0.041 \\
\hline \multirow{4}{*}{14} & 100 & 0.057 \\
\hline & 300 & 0.052 \\
\hline & 700 & 0.049 \\
\hline & 1000 & 0.035 \\
\hline \multirow{4}{*}{20} & 100 & 0.050 \\
\hline & 300 & 0.049 \\
\hline & 700 & 0.032 \\
\hline & 1000 & 0.015 \\
\hline
\end{tabular}


Table 4.- Average of the loss mass in \% of the PLA samples treated with atmospheric plasma at different distances nozzle/substrate and variable traverse speeds.

\begin{tabular}{|c|c|c|c|c|}
\hline $\begin{array}{l}\text { Nozzle-substrate } \\
\text { distance (mm) }\end{array}$ & $\begin{array}{l}\text { Advance rate } \\
\qquad\left(\mathrm{mm} \cdot \mathrm{s}^{-1}\right)\end{array}$ & $\begin{array}{c}\gamma_{\mathrm{s}} \\
\left(\mathbf{m J} \cdot \mathbf{m}^{-2}\right)\end{array}$ & $\begin{array}{c}\gamma_{\mathrm{s}}^{\mathbf{p}} \\
\left(\mathbf{m J} \cdot \mathbf{m}^{-2}\right)\end{array}$ & $\begin{array}{c}\gamma_{s}^{d} \\
\left(\mathbf{m J} \cdot \mathbf{m}^{-2}\right)\end{array}$ \\
\hline \multirow{4}{*}{10} & 100 & 58.9 & 32.8 & 26.1 \\
\hline & 300 & 52.6 & 26.2 & 26.4 \\
\hline & 700 & 46.4 & 20.5 & 25.9 \\
\hline & 1000 & 41.5 & 15.3 & 26.2 \\
\hline \multirow{4}{*}{14} & 100 & 48.2 & 18.9 & 29.3 \\
\hline & 300 & 45.4 & 18.0 & 27.4 \\
\hline & 700 & 41.6 & 13.9 & 27.7 \\
\hline & 1000 & 39.3 & 12.1 & 27.2 \\
\hline \multirow{4}{*}{20} & 100 & 46.7 & 13.6 & 33.1 \\
\hline & 300 & 43.3 & 11.6 & 31.7 \\
\hline & 700 & 39.1 & 8.3 & 30.8 \\
\hline & 1000 & 37.8 & 6.9 & 30.8 \\
\hline
\end{tabular}

